\title{
ALGUNES DADES SOBRE LA INFLUÈNCIA DE LES PROSES MITOLÒGIQUES DE CORELLA A LES TRANSFORMACIONS DE FRANCESC ALEGRE*
}

\author{
SOME NOTES ON THE INFLUENCE OF JOAN ROÍS \\ DE CORELLA'S MYTHOLOGICAL FABLES \\ IN FRANCESC ALEGRE'S TRANSFORMACIONS
}

\section{Gemma Pellissa Prades \\ Universitat de Barcelona \\ gemmapellisa@gmail.com}

Resum: A través d'una comparació entre les proses mitològiques de Corella i les Transformacions de Francesc Alegre l'autora mostra que Alegre utilitza materials provinents de les Lamentacions i del Parlament en casa de Berenguer Mercader de Joan Roís de Corella per a la traducció catalana medieval de les Metamorfosis d'Ovidi, escrita entre I472 i I482, aproximadament. Així mateix, s'apunten indicis pel que fa a la influència del Raonament de Telamó $i$ Ulisses a les Transformacions. Així, malgrat que Alegre parteix del poema llatí, completa la traducció amb la integració d'altres fonts que decideix no explicitar (Bonsignori, Corella). Finalment, es detecta un indici que apuntaria al fet que Corella pogués haver consultat l'adaptació italiana de Bonsignori o una versió d'Ovidi que en depengués.

Paraules clau: Francesc Alegre, Joan Roís de Corella, traduccions al vernacle, recepció d'Ovidi, traduccions catalanes medievals, literatura comparada.

Abstract: This article establishes a comparison between Joan Roís de Corella's mythological fables and Francesc Alegre's translation of Ovid's Metamorphoses into Catalan. The author proves by

$\left.{ }^{*}\right)$ La recerca que presentem ací ha rebut el suport del programa postdoctoral Beatriu de Pinós de la Secretaria d'Universitats i Recerca del Departament d'Empresa i Coneixement de la Generalitat de Catalunya, del programa postdoctoral Juan de la Cierva del Ministeri de Ciència, Innovació i Universitats i del projecte Corpus Digital de Textos Catalans de l'Edat Mitjana i el Renaixement CDTC (FFI 2014-53050-C5), dirigit per Lola Badia. Com a resultat dels contractes postdoctorals esmentats, properament es publicarà l'edició crítica i anotada de les Transformacions d'Alegre. L'autora agraeix, així mateix, els comentaris dels avaluadors de l'article i la col-laboració de Martí Duran en el projecte. 
Gemma Pellissa Prades

Algunes dades sobre la influència de les proses mitològiques de Corella

a les Transformacions de Francesc Alegre

means of examples that Alegre drew on Corella's Lamentacions and Parlament en casa de Berenguer Mercader while translating his work between circa I 472 and I492. Further, he may have also known Corella's Raonament de Telamó $i$ Ulisses. Thus, even if Alegre based his text on the Latin poem, he surely completed the translation with the aid of other sources that are not made explicit, such as Bonsignori and Corella. In addition, the author suggests that Corella might have known and used Bonsignori's Italian compilation or another version of Ovid's poem which depended on it.

Key words: Francesc Alegre, Joan Roís de Corella, vernacular translations, the reception of Ovid, medieval Catalan translations, comparative literatura.

\section{$\operatorname{cosects}$}

\section{INTRODUCCIÓ}

El 24 d'abril de 1494 el llibreter i impressor Pere Miquel publicà a Barcelona les Transformacions de Francesc Alegre en una tirada de Iooo exemplars (Hernando \& Delgado 2002: 514-516), dels quals se n'han conservat divuit (Avenoza, Soriano \& Beltran 1997: BITECA manid I776). ${ }^{1}$ Segons argumenta Torró (1994), la primera versió de l'obra hauria estat redactada entre c. I472 i I482; posteriorment, Alegre l'hauria revisat per a la impremta. L'obra consta d'una traducció en prosa de les Metamorfosis d'Ovidi al català i d'una segona part en la qual s'ofereix un comentari dels mites a partir de les Genealogiae deorum de Boccaccio (Badia 1986).

Tot i que Alegre esmenta a l'epíleg l'existència d'una traducció catalana prèvia d'uns quants llibres del poema llatí a cura de Francesc Galceran de Pinós (c. I4I6-I475), no se’n té cap notícia més enllà del que en diu Alegre (Cabré, Ferrer \& Pujol 2oIr: TCMP io.I.I). ${ }^{2}$ De fet, l'autor de les Transformacions manifesta la intenció de superar les traduccions anteriors en català (Galceran de Pinós), castellà i italià (Giovanni Bonsignori, Ovidio Metamorphoseos Vulgare, c. 1375-1377) perquè les tres versions s'havien

I. S'ha preservat el document de participació de l'autor, l'impressor i un jove amic d'Alegre en el repartiment de la inversió i dels beneficis del llibre (Hernando \& Delgado 2002: 514-516). Segons Rubió i Balaguer (I993: II2-II3) aquest seria el primer cas documentat a la Corona d'Aragó d'un autor que paga per la impressió d'obra pròpia.

2. Francesc Galceran de Pinós, marit de Beatriu de Pinós, pertany a l'entorn de Carles de Viana, en motiu de la mort del qual sembla que escriví una Complanta (Duran \& Solervicens 1996: 40). És autor d'una de les respostes dels Deseiximents contra Fals Amor que Pere Pou convocà el I458 des del monestir de Valldonzella (Avenoza, Soriano \& Beltran 1997: BITECA bioid 2905). Així mateix, Martí (I997: 497) el proposa com a possible compilador del Cançoner del marquès de Barberà, datat als anys $70 \mathrm{del} \mathrm{s}$. Xv. 
basat en un text intermediari —en realitat, dos textos autònoms del mateix autor escrits en llatí medieval—: l'Expositio i les Allegorie de Giovanni del Virgilio (I322-I323). Així, Guthmüller (I997: 67 i 85) destaca la singularitat de la traducció d'Alegre perquè fou traduïda directament a partir del poema llatí, mentre que les versions francesa i italiana de l'obra que circularen a través d'incunables no tenien Ovidi com a font principal. Amb tot, Alcina (1998) va provar mitjançant dos exemples del llibre I que Alegre també havia consultat la traducció italiana de Bonsignori. En efecte, la influència d'aquesta obra és constant, encara que discreta, al llarg dels quinze llibres de la primera part de les Transformacions i fins i tot s'ha identificat en el comentari que constitueix la segona part de l'obra, les "Al-legories e morals exposicions» (Pellissa Prades 2017). ${ }^{3}$ Però Alegre tria els autors — més ben dit, les auctoritates — que explicita en la pròpia producció literària; per exemple, Petrarca a la prosa sentimental Somni de Francesc Alegre recitant lo procés de una qüestió enamorada (c. I475) o Giovanni Boccaccio a les "Al-legories e morals exposicions». Ambdós autors apareixen com a personatges dins del marc de ficció alhora que Alegre n'introdueix citacions literals breus, que tradueix, i en reelabora motius. En canvi, amaga l'ús d'altres fonts com Bonsignori i, segurament, Joan Roís de Corella a les Transformacions, com tot seguit s'analitzarà. De fet, a la Faula de Neptuno i Diana (I482-I486), una prosa sentimental de caire mitològic atribuïda a Francesc Alegre (Torró I994), s'hi ha detectat la influència de la Tragèdia de Caldesa de Corella, tant en les sentències apocalíptiques en estramps que pronuncien les Parques (Torró I994) com en l'argument basat en la prostitució de la infidel Diana a canvi de diners, el joc lingüístic amb l'antropònim de la protagonista, la possibilitat d'interpretar la història en paràmetres realistes, l'actitud desenganyada de la passió amorosa, l'exemplum i el narrador en primera persona (Pellissa Prades 20I6: 217). Així mateix, la falta de Diana és immortalitzada amb un rètol clavat a la pedra negra en la qual s'ha transformat per a indicar la causa del càstig: la prostitució de l'amor (Pellissa Prades 20I6: 20I).

Ja era tota rocha, e no blancha [...]. E perquè no manchàs alguna part del dir de les tres fades, hun títol novament sculpit de mostra de gòtigas, per l'orla de aquella nova pedra, a hon tots quants entraven legían tals paraules: «Perqué vené ab preu ço que.l grat compra, denunciant a tots la causa de son mal».

3. Hi ha indicis que apunten que a les "Al-legories e morals exposicions» Alegre també usa lliçons que provenen de les Allegorie de Giovanni del Virgilio, segurament reportades als marges de la còpia que contenia el text de Bonsignori (Pellissa Prades 20I7: 466-467).

Caplletra 66 (Primavera, 2019), p. 15-32 
Gemma Pellissa Prades

Algunes dades sobre la influència de les proses mitològiques de Corella

a les Transformacions de Francesc Alegre

Aquest tret recorda l'explicació que afegeix Corella sobre la metamorfosi de Mirra a les Lamentacions, presentada com a exemplum (Martos 200rb: I84):

\begin{abstract}
E, perquè les altres dones, hohint la legea de ma benvolença, no creguessin la major part ésser faula ho, almenys, prenguessen esmena mirant la justa penitència de mon peccat, plagué als déus mudar lo meu cos en arbre de mon propi nom [...], testifficant la mia desaventurada vida.
\end{abstract}

Finalment, la Faula de Neptuno i Diana és l'única prosa mitològica del corpus d'Alegre i, de retruc, del corpus de la ficció sentimental catalana a excepció de les obres de Corella. ${ }^{4}$

En efecte, més enllà dels paral.lelismes entre les dues obres, convé destacar que una part important de la producció en prosa d'ambdós autors s'inscriu dins de l'anomenada ficció sentimental catalana del s. xv. En el cas de Corella, les proses mitològiques i la Tragèdia de Caldesa i en el d'Alegre, el Raonament, la Requesta, el Somni, el Sermó d'amor i la Faula de Neptuno i Diana, compostes entre c. I472 i I486. 5 Per tant, utilitzen una sèrie de recursos propis de les obres sentimentals: la priorització de les descripcions i expansions sentimentals per damunt de l'acció, la riquesa retòrica, l'ús de la primera persona, la combinació del vers i la prosa i l'abundància d'imatgeria sentimental (planys, sospirs, el foc i les flames d'amor, la Fortuna). A més, comparteixen un model lingüístic.

Això també es fa palès a les Transformacions, en què Alegre amplifica certs passatges que li permeten afegir una expansió sentimental o conceptualitzar la passió amorosa en un incís; en algunes ocasions, podria ser que l'autor se servís de Bonsignori i fins i tot de Corella per a fer-ho.

En aquest article s'exposaran els paral-lelismes que he detectat entre les proses mitològiques de Joan Roís de Corella i els episodis corresponents de les Transformacions, sense entrar en les «Al-legories e morals exposicions». Així mateix, se subratllaran els casos en què la dependència sembla segura. ${ }^{6}$ En aquesta línia, Compagna (20I4) va comparar el mite de Medea i Jàson en Alegre (traducció i comentari) amb Escriu Medea a les dones la ingratitud e desconeixença de Jason de Corella (I456-I458) i va concloure que, mentre

4. De fet, el corpus sentimental d'Alegre s'ha transmès en un testimoni únic a través del manuscrit del Jardinet d'orats, conservat a la Biblioteca de Reserva de la Universitat de Barcelona I5I, en el qual Narcís Gual també va copiar la Lamentació de Biblis, les Lamentacions, La història de Leànder i Hero i la Tragèdia de Caldesa de Joan Roís de Corella.

5. Per a la datació de les proses mitològiques de Corella i l'estudi de les fonts, veg. Martos (200Ia). Per a la darrera síntesi sobre el corpus de l’autor, veg. Francesc J. Gómez (2015).

6. No ens deturarem en les proses mitològiques de Corella de les quals no s'han detectat préstecs a les Transformacions. 
que el valencià fa una reelaboració intensa de les fonts, Alegre no sembla distanciar-se dels models que segueix (Ovidi, Boccaccio i la resta d'autoritats que intervenen com a personatges a les «Al-legories e morals exposicions»). Si bé Corella va més enllà de les pràctiques d'exposició i traducció dels mites llatins al vulgar, analitzades per Pujol (2002), Alegre també integra fonts que no explicita amb un objectiu diferent: mantenir la fidelitat al poema llatí sense renunciar a la comprensió plena de les referències i de les relacions causa-efecte de la història — més evidents en la narració en prosa - per part del lector coetani. D'aquesta manera, introdueix detalls puntuals als episodis mitològics sense incórrer en digressions que es desviïn del fil ovidià, a diferència de la versió italiana de Bonsignori, de la qual Alegre també se separa mitjançant l'ús de l'estil elevat de la prosa d'art. Com s'ha esmentat, el desenvolupament d'una prosa rica i elegant que vehicula la narració afavoreix l'amplificació sentimental en moments determinats de la traducció, la reelaboració retòrica de certes intervencions en estil directe que Ovidi reportava en estil indirecte i viceversa. ${ }^{7}$ Així mateix, l'organització en capítols dins de cada llibre fa que el traductor treballi les transicions d'un capítol a l'altre. Per contra, sovint alleugereix el text de símils, d'enumeracions i de repeticions.

El fet que Alegre conegui l'obra de Joan Roís de Corella i l'empri com a model per a construir la Faula de Neptuno i Diana, en la qual també usa passatges de la pròpia traducció de les Metamorfosis que han ajudat a datar-la (Torró i994; Pellissa Prades 2016), fa que la comparació entre els mites que el valencià reelabora en forma de "poètica ficció» i els episodis corresponents de les Transformacions sigui una tasca necessària per a determinar si influïren en la traducció d'Alegre. Cal tenir en ment, però, que la premissa principal d'Alegre és la fidelitat al poema llatí, encara que utilitzi altres textos per a completar l'obra. L'ús discret de les fonts addicionals, així com la presència d'una font comuna entre Corella i Alegre, dificulta l'empresa. Es tracta de les Genealogiae deorum de Boccaccio, que el mateix Alegre indica com a font principal del comentari, però que podria haver emprat també a la primera part de l'obra com a text de consulta, igual que fa amb Bonsignori al llarg de les Transformacions. De la mateixa manera, s'ha de tenir en compte que tant Corella com Alegre devien conèixer les Metamorfosis a través de manuscrits tardans amb comentaris i glosses que podien coincidir. A continuació, examinaré fragments de les Transformacions en els quals Alegre hauria pogut tenir en compte les proses mitològiques de Corella. En l'apartat que segueix es presenten els exemples en els quals, malgrat les similituds, la depen-

7. Alegre critica a l'epíleg la traducció ad verbum, que ell no segueix, atès que «no sol lo metre latí és quasi impossible posar en vulgar prosa, seguint-lo com està, mes la prosa imperfeta e fora de compàs se amostra tostemps que és seguida paraula per paraula» (Duran \& Solervicens i996: 40). Així, té una major llibertat d'estil.

Caplletra 66 (Primavera, 2019), p. 15-32 
Gemma Pellissa Prades

Algunes dades sobre la influència de les proses mitològiques de Corella

a les Transformacions de Francesc Alegre

dència Corella-Alegre no es pot provar de forma contundent. A l'apartat següent s'hi analitzen dos casos en els quals la influència de Corella (Lamentacions i Parlament a casa de Berenguer Mercader) a les Transformacions és clara.

\section{SEMBLANCES ENTRE LES PROSES MITOLÒGIQUES DE CORELLA I LES TRANSFORMACIONS}

Les Lamentacions de Joan Roís de Corella narren tres mites que provenen de les Metamorfosis d'Ovidi: els episodis de Mirra, Narcís i Píram i Tisbe, en aquest ordre. En aquest apartat hom s'ocuparà dels dos darrers.

Al llibre III de les Metamorfosis s'hi explica el mite de Narcís. Ovidi introdueix l'actitud de l'adolescent envers l'amor amb aquests versos (Trepat \& Saavedra 1929: llibre III, vv. 35I-355):

Namque ter ad quinos unum Cephisius annum / Addiderat poteratque puer iuuenisque uideri; / Multi illum iuuenes, multae cupiere puellae; / Sed fuit in tenera tam dura superbia forma, / Nulli illum iuuenes, nullae tetigere puellae. ${ }^{8}$

que Alegre (I494: f. 24v [25v]) tradueix així:

Essent Narciso de edat de vint anys, per la sua gentilesa fon per moltes volgut, mes, a tant la vana presumpció que de gentil tenia bastà, que neguna estimant digna de son acost, retret en los boscatges per fugir a les dones, seguí la vida de Diana.?

L'esment a la vida de castedat simbolitzada per la deessa Diana no figura en Ovidi i tampoc no apareix en Bonsignori, però sí que és una constant en l'elaboració d'aquest mite per part de Corella a les Lamentacions (Martos 200rb: I85):

Partint-me de aquella poch ansiosa edat de adolescència, la mia bellesa tant augmentava, que la bella reyna Juno, més de mi que del gran Júpiter, fóra contenta. Mas yo, curant poch de

8. «Perquè a tres vegades cinc havia afegit el Cefisi un any i podia semblar infant i home; molts minyons el desitjaven i moltes donzelles; però en el tendre cos hi havia un orgull tan dur que cap minyó ni cap donzella l'havia tocat» (Trepat \& Saavedra I929: vol. I, 66).

9. Per a la referència a l'edat, veg. Moncunill (2015: 197). Quant al tractament de l'homosexualitat, Alegre es mostra més pudorós que Bonsignori: «non solo le polzelle, ma li gioveni eran di lui innamorati» (Ardissino 200I: 196), tot i que, a diferència de Corella, manté l’ambigüitat sobre el sexe de la imatge reflectida a l'aigua. En Corella, Narcís narra en primera persona com s'enamorà del que pensa que és una nimfa, interpretació extreta de les Genealogiae deorum de Boccaccio, font principal d'Alegre al comentari. Corella també prescindeix de la presa de consciència per part del jove que la imatge que veu és el propi reflex, tret que també manca en altres versions medievals del mite (Vinge 1967). 


\section{Gemma Pellissa Prades \\ Algunes dades sobre la influència de les proses mitològiques de Corella a les Transformacions de Francesc Alegre}

obehir a Venus, en la apartada religió de Diana, ab gran supèrbia me defenia de les enamorades fleixes de Cupido.

Alegre utilitza la mateixa perífrasi mitològica que el valencià, però, atès que es tracta d'un tòpic, no és suficient per a establir una relació de dependència entre les dues obres.

També en aquesta composició, després del mite de Narcís, Corella explica la història de Tisbe, que Ovidi relata al llibre Iv de les Metamorfosis. En aquest episodi no hi ha paral.lelismes lèxics entre Corella i Alegre. Això no obstant, la traducció comparteix elements amb el mite de Corella que es diferencien del poema llatí. Vegem, abans, la traducció d'Alegre (I494: f. 28r [29r] - 29v [30v]):

Capítol segon, en qui se tracte la mort de Píramo i Tisbe ab la conversió de les mores blanques en vermelles

-En la gran Babilònia, la antiga ciutat que cenyí de fort mur la reyna Semíramis, mare del noble Nino, nasqueren dos infants de egual gentilesa, passant la un, que era nomenat Píramo, los fadrins en bellesa y l'altre, qu'era Tisbe, les donzelles de aquella edat. Les cases de lurs pares una sola paret tenia departides y, com és de costum que en los xichs demostra la natura ses forces descubertes e inclinacions [28v [29v]] seguides sens cautela, en la lur infantesa presos d'aquell grat qui sovint nos governa, donaven molts senyals de amor verdadera y, crexent la edat, més tal amor crexia. Per on, apersebits del foch ensès, los pares assajaren vedar lo que fins vuy és a tots impossible. De grat egual encesos, egualment se amaven y per çò quant podien ab senyals reparaven la falta del parlar, car lo foch més cubert major flama espira.

«En la paret comuna qui les cases partia era una fenella, la qual en tants cents anys no era stada vista. Mes, què no sent amor? Aquests enamorats primer la descobriren, fent per ella camí al so de lurs paraules. Deya.l graciós jove: «O, crueltat de pares, qui posa tal contrast a tan censera amor?», y replicava ella: «Tostemps é hoït dir que dues voluntats a una fi girades les coses molt difícils y quasi impossibles acaben sens treball. No cansem de pansar remeys al present mal». «Ha, Tisbe!», deya Píramo, «totes les nits me fugen seguint tal pensament y remey no sé veure sens perill de la vida y tacha de la honra». E axí, sovint acostats a la creta, detenían lo dia ab semblants parlaments y, alenant la un a l'encontre de l'altre, ab calor de inflamat alè descobria quascú çò que.n secret portava. Girats a la paret sovint axí li dèyan: «O, paret anujosa, per què poses empaix a nostres voluntats? Què seria a tu consentir a nosaltres que de prop nos tocàssem? $\mathrm{O}$, si asò·t par molt, almenys nos consentisses sentir aquell delit que.l besar representa. Però no·t som ingrats d'aquest graciós do que fins avuy rebem, per la tua ubertura reportant les paraules dels dos encarcerats». Y, prenent comiat, quascú d'aquells besava la part de la paret qui li era més prop.

«Aquesta fon la vida dels dos enamorats y durà per gran temps fins que.s seguí un dia, havent la clara alba apartades del cel les reluints esteles e lo sol ab sos raigs començant a secar la humida rosada, que, Tisbe, anujada dels pensaments, del lit se levà $y$, ab ardent desig al forat acostada, estava esperant si veuria a Píramo, qui, per aquella mateixa ocasió al dit loch arribat, posat en maravella per trobar-hi a ella, li començà a dir: «Basca de veure-us, delicada senyora, à cuytat mon levar, dient-me l'espirit, que.l vostre és conforme, que ya érau ací». "Si tan gran ànsia com les raons senyalen tinguésseu vós de mi», dix la enamorada, «en alre la mostràreu, trobant algun camí per finar aquest mal. No teniu pietat de mi, desventurada, qui per vós so enclosa a no poder exir? Si prest no·m soccorreu, rosegant-me

Caplletra 66 (Primavera, 2019), p. 15-32 
Gemma Pellissa Prades

Algunes dades sobre la influència de les proses mitològiques de Corella

a les Transformacions de Francesc Alegre

amor com rosega lo verme al fust qu'és vell, me tornarà tost cendra y vós sens mi viureu desanciat».

«Torbàs de hoir tal de la que més amava lo jove, turmentat y no de menós mals que la que l'enculpava, exint ab tals paraules: «Amor me fa tant vostre que sent lo que sentiu e ya pensat tenia camí de desviar lo anuig que.ns turmenta, mes no.l gosava dir. Si a vós parrà bé, yo seria de parer que, en la vinent nit, vós en-[29r [3or]]ganeu qui us guarde ab simulat dormir y, quant la vera son detenint los lurs ulls haurà privat los senys de lurs propis officis, secretament obrint la porta de la casa, d'ella hiscau y de tota ciutat. E per escusar treball en quascú de nosaltres, tindria yo per bo que.l qui serà primer a l'altre esperàs al sepulcre de Nino, amagat sots la ombra de l'arbre. Y havia-y un alt morer, vehí de una font gelada, ab branques carregades de mores blanques». Plagueren molt a Tisbe las raons esplicades, en la fi de les quals, prenent lo comiat que acostumat havían, restaren esperant la ombra de la nit, inculpant ab murmur los cavalls del gran Febo perquè ab cansat pas duraven tant lo dia.

«Ja cuytava lo sol per mullar-se en lo pèlech de l'antich Acteano y la espessa ombra occupava la terra, quant Tisbe, esvellada, hisqué fora la casa, enganant a sos pares. Y ab lo cap cubert, armada del gosar que amor li donava, arribà al sepulcre y, sota aquell arbre, on Píramo no era, lo esperà asseguda; de on, mirant sovint a totes parts com sol fer qui espera cosa molt desitjada, per los raigs de la luna descobrí de molt luny una cruel leona venint ab cuytat pas devers aquella font per deposar la set. Fugí la temerosa, dexant aquell gosar que poch ans tenia, en una fosca cova, e caygué-li del cap lo vel ab què-s cobria; del qual, gens no curant, sol atengué en reparar tan eminent perill. Aprés que la leona ab aygua abundant hagué la set dexada, tornant-se en lo bosch, trobà lo vel de Tisbe y, ab dents rabiosos, tot lo escorterà, dexant-lo ple de sanch.

«Vengué en aquell temps Píramo molt cuytat, tement lo mal vehí, e, mirant en la terra les petjades molt fresques de l'animal salvatge e lo vel esquinçat ab la color mudada, dix les següents paraules: «Y, donchs, axí serà que una sola nit perdrà dos qui se amaven! Ja almenys fosses justa, o, cruel mort, matant a mi, culpable, y a ella dexant, qu'era digna de viure. $\mathrm{O}$, mesquina de tu, que yo so lo homeyer! Yo so lo qui t'é morta, qui doní lo consell que venguéssem ací y no y venguí primer. $\mathrm{O}$, afamejats leons, qui sots aquesta roca fon lo vostre estatge, pus que ja us sou pascuts de aquella gentil per qui en algun preu tenia yo la vida, veniu ara per mi, escorterau mos membres e menjau-me lo cor! Mes de home de poch és desijar la mort, pus està en sa mà posar fi a la vida». Y ab rabiós ànimo pren lo vel esquinçat, anant ab cuytats passos fins a la font qui sots l'arbre estave. Mil vegades besa aquell dolorós vel, mullant-lo ab l'aygua de ses abundants làgremes. $\mathrm{Y}$, besant $\mathrm{y}$ plorant, tenint $\mathrm{ab}$ la mà dreta lo mantí de la espasa de qui era cenyit, ab la punta de aquella se ferí per los pits y aprés, arrencant-la, escampant molta sanch, restà quasi mort, agegut en la terra, umplint lo cel de piadosos crits. La rael de aquell arbre, mullada de la sanch, tenyí les mores blanques de vermella color.

«Durant aquestes coses, no encara del tot de por assegurade, vengué la trista Tisbe, tement de enganar a-[29v [30v]] quell que més amave, cercant $\mathrm{ab}$ ànimo no reposat y ab ulls de gran basca la vista de aquell qui la mort li cuytà. E, venint, raonava axí ab si mateixa: «Com me alegraré, arribada a Píramo, podent-li recitar lo perill qu'é fugit! Com me burlaré d'ell, de ésser pus diligent! Com faré més amable per tots aquests treballs ma ferma voluntat». E, axí raonant, regonegué lo loch y, mirant aquelles mores ab la color mudada, fon posada en dupte. Y mentre que duptava, girada al través, viu lo cors sangonós, qui encara polsava. Espantada, tornà lo peu arrera; mes, pus que conegué ésser lo que amava, batés los pits y cara y arrencàs los cabells. Y abraçada $\mathrm{ab}$ lo cors qui moria, mesclà les sues làgremes $\mathrm{ab}$ la sanch de aquell. Besà la freda boca, cridant ab alta veu: «Píramo, mesquí, quin cas te n’ha portat? Píramo, respon la tua Tisbe: crida, hou-me com acostumes, alça un poch los ulls al nom de Tisbe». 


\begin{abstract}
«Aquells, gravats per mort, alsà encara Píramo y, vista aquella de qui prenia vida, los tornà a tancar ab eternal eclipsi. Mirà ella lo vel y la espasa en la mà de aquell, d'on conegué la causa de mort tan desestrada y dix semblants paraules: «O, desaventurat, amor y la mà tua t’an portat a morir. Yo, pus que tinch la mà sana par a matar y la amor no menys forta, te seguiré morint y seré dita causa y companyona de mort tan miserable. Ay, trista, que no porà la mort apartar-te de mi, qui sol yo esperava tengués poder de lunyar-me de tu. $\mathrm{O}$, miserables pares, siau pregats de açò: que.ls que amor tan certa y la hora derrera han volgut ajustar, vullau posar ensemps en una sepultura. Y tu, arbre mal vist, qui ab los teus grans rams ara cobres un mort y tost cobriràs dos, té per tostemps senyal ab les mores vermelles de nostra trista mort».

«E havia de tal manera dit quant, prenent la dasijada espasa, qui de la fresca sanch de Píramo suava, los pits se'n travessà. Y estech complaguda sa derrera demanda per los pares y déus, durant en lo morer fer les mores tenyides de tan amable sanch y soterrant lurs cossos tots dintre una tomba.
\end{abstract}

Pel que fa als elements comuns, en primer lloc, figura la imatge de la presó metafòrica en la qual viuen inicialment els enamorats («per la tua ubertura reportant les paraules dels dos encarcerats», Alegre I494: f. 28v [29v] / «exint del carçre del ventre de nostres mares»; «ixquí de la carçre de la trista casa», Martos 200ıb: I9I i 196).

En segon lloc, la conversa en la qual els joves prenen la decisió de fugir és reportada en estil indirecte en Ovidi, mentre que Corella i Alegre la transformen en estil directe; s'afavoreix així l'expansió sentimental. Tal com s'ha indicat, l'ús d'aquest procediment no és una excepció a les Transformacions. En el cas de Corella, el diàleg és més extens, atès que els enamorats intervenen en dues ocasions cadascun amb discursos molt elaborats. Però en ambdues versions hi ha un èmfasi en el dolor compartit i s'explicita que Tisbe empeny Píram a la trobada, encara que Ovidi, més endavant, suggereixi la responsabilitat del noi en l'empresa. En Corella, l'enamorada — que narra la història en primera persona - pren la iniciativa fatal i proposa el lloc on han d'acudir, malgrat els dubtes de Píram. ${ }^{10}$ Alegre, encara que més endavant recuperi el sentiment de culpa de Píram, fa que sigui Tisbe qui l’inciti ("Si tan gran ànsia com les raons senyalen tinguésseu vós de mi", dix la enamorada, "en alre la mostràreu, trobant camí per finar aquest mal" ", Alegre I494: f. 28v [29v]). Per això l'enamorat, que d'entrada no gosava, planteja una solució al problema.

En tercer lloc, quan Tisbe, salvada del perill de la lleona, surt de l'amagatall per retrobar-se amb Píram, Ovidi escriu els versos següents, en estil indirecte: «Illa redit iuuenemque oculis animoque requirit, / Quantaque uitarit narrare pericula gestit»

Io. Joanot Martorell aprofita aquest diàleg de les Lamentacions al capítol 2io del Tirant lo Blanc (Hauf I995: 84-86).

Caplletra 66 (Primavera, 2019), p. 15-32 
Gemma Pellissa Prades

Algunes dades sobre la influència de les proses mitològiques de Corella

a les Transformacions de Francesc Alegre

(Trepat \& Saavedra I929: IV, vv. I29-I30). ${ }^{11}$ Tant Corella com Alegre amplifiquen el sentit dels versos a través del monòleg, tot i que el contingut no hi coincideix:

\begin{abstract}
O! Com contaré a Príamo los perills en què·m só vista? E, seràm pres en comte de infinida amor. E, si no.m creu, mostrar-li é los passos de la lleona».

(Martos 200Ib: 197)

Com me alegraré, arribada a Píramo, podent-li recitar lo perill qu'é fugit! Com me burlaré d'ell, de ésser pus diligent! Com faré més amable per tots aquests treballs ma ferma voluntat.

(Alegre I494: f. 29v [30v])
\end{abstract}

De fet, Corella reutilitza aquest motiu al Leànder i Hero, tot i que en estil indirecte (Martos 200Ib: 197).

De la mateixa manera que ocorre amb les Lamentacions, les Transformacions d'Alegre també presenten similituds amb alguns dels mites que es conten els interlocutors del Parlament en casa de Berenguer Mercader de Corella. D'acord amb l'estructura dels convivia, el relat que tria Joan de Pròxida com a exemplum és la història de Tereu, Procne i Filomela, que Ovidi narra al llibre vi. Quan Procne pregunta al marit on és la germana, a qui havia enviat a cercar, Alegre (I494: f. 53v [52v]) escriu: «Plora lo ficte Tereu y diu-li com és morta del treball de la mar», mentre que Ovidi només explica: «at ille / Dat gemitus fictos commentaque funera narrat» (Trepat \& Saavedra I930: vI, v. 564-565). ${ }^{12}$ És a dir que Alegre aclareix la raó que Tereu dona per a la mort de Filomena, encara que el detall no figuri en Ovidi ni tampoc en Bonsignori: (“Filomena, tua sorella, è morta” e cominciò a piangere per dare de ciò ferma fede», Ardissino 200I: 322). Aquesta informació ja figura a la faula de Corella: «a la muller féu creure la germana Philomena de mal de la spantable mar havia dexat la vida» (Martos 20orb: 276), però també a la Genealogiae deorum de Boccaccio, XI, 8 (Martos 20I3), que Alegre empra a la segona part de l'obra.

Per tant, és evident que Alegre completa el passatge amb un detall que no figura al poema d'Ovidi, segurament per fer-lo més aclaridor, com fa en altres ocasions. En aquest cas, una de les fonts que sabem que va consultar (Bonsignori) no conté la informació; però sí que la inclouen les Genealogiae deorum de Boccaccio, que coneixen tant Corella com Alegre mateix, el qual se'n serveix a les «Al-legories e morals exposicions». També la recull el Parlament. En definitiva, podria ser que Corella i Alegre compartissin una font comuna (Boccaccio) o que Alegre la incorporés a partir

II. «Ella torna i cerca el minyó amb els ulls i amb el cor i es deleix per contar-li els perills que ha evitat» (Trepat i Saavedra 1929: vol. I, 83).

I2. «I ell fa gemecs fingits i conta una mort inventada» (Trepat \& Saavedra I930: vol. II, 20). 
de Corella. Certament, el fet que els dos textos reportessin aquesta informació podria haver influït en la decisió d'Alegre d'incloure-la. Amb tot, encara hi hauria una tercera possibilitat que no es pot descartar: l'existència d'aquest detall en forma de glossa al manuscrit d'Ovidi que Alegre va consultar per traduir el poema.

Encara quant a aquest mite, Martos es fixa en la descripció que el Parlament ofereix de la transformació de Procne en oreneta, que resumeix en quatre trets: (a) la negror del cos de l'ocell, $(b)$ la taca roja al pit com a senyal de la sang vessada del fill (que ja figura en Ovidi), (c) la gonella-cua esquinçada i $(d)$ el fet que habiti als palaus (i no a les cases en general). L'estudiós situa l'origen del primer i del darrer trets en Boccaccio, però no troba explicació per a la cua esquinçada, que en canvi Ardissino (200I: 334) considera una aportació pròpia de Bonsignori: «allora gionse Tereo e presela de dietro per li panni em credendola avere presa, sì gli rimase in mano el ghirone de dietro della gonella. Allora nel cadere gli dii, avendo de lei misericordia, la convertirono in rondine, ed ave così retagliata la coda per quello ghirone della gonella, la quale remase in mano allo re Tereo» (200I: 325). ${ }^{13}$ Alegre (I494, f. 54r [53r]) no inclou aquesta característica, tot i que indica que Procne porta «negra vestidura». Martos (2013) afegeix més exemples per demostrar la influència de l'obra de Boccaccio en la narració d'aquest mite per Corella, però no són aplicables a Alegre. Amb tot, caldria dur a terme una comparació exhaustiva entre les Transformacions i la Genealogiae deorum per a comprovar si hi ha préstecs a la primera part de l'obra, la traducció, que no siguin compartits amb Corella. Això faria pensar en una font comuna per als dos autors.

S’esdevé el mateix amb un detall afegit al mite de Cèfal i Procris, que es recull al llibre viI de les Metamorfosis. Incitat per Aurora, Cèfal posa a prova la fidelitat de l'esposa. Ovidi indica com ho fa per a no ser reconegut quan es presenta a casa «inmutatque meam [...] figuram» (Trepat \& Saavedra I930: vII, v. 722). ${ }^{14}$ En canvi, Alegre (I494: f. 63r [62r] - 63v [62v]) especifica: "Y axí transformat en figura de un estrany mercader». L'afegit no apareix en del Giovanni del Virgilio («Mutaui ergo

I3. El fet que Alegre indiqui a l'epíleg de les Transformacions que la traducció de Francesc Galceran de Pinós s'havia basat en Bonsignori, de la mateixa manera que el traductor d'una versió castellana de les Metamorfosis, significa que l'obra de Bonsignori era coneguda en forma manuscrita abans de 1475 a l'entorn del príncep de Viana i a la Corona d'Aragó. Si Corella l'hagués consultat, aquesta datació s'hauria d'avançar als anys 50 del s. xv. Falta un estudi sobre la circulació del text fora d'Itàlia i una anàlisi de les diferències textuals entre el segon estadi de transmissió de l'obra, al qual pertany el text imprès a partir de I497, editat per Ardissino (200I), i la primera branca de l'stemma, tal com m’ha fet notar Elisa Guadagnini. La recerca en aquesta línia fa esperar afirmacions concloents. No es pot descartar tampoc que aquest detall hagués arribat a Corella a través d'una altra font, del manuscrit d'Ovidi consultat o fins i tot que l'hagués llegit a la traducció parcial de Francesc de Pinós o a la versió castellana de Bonsignori.

I4. «I canvia [...] la meva figura» (Trepat \& Saavedra I930: vol. II, 47).

Caplletra 66 (Primavera, 2019), p. 15-32 
Gemma Pellissa Prades

Algunes dades sobre la influència de les proses mitològiques de Corella

a les Transformacions de Francesc Alegre

me in vestibus moribus et in facie», Ardissino 200I: 378) ni tampoc en Bonsignori («io me trasmutai in vesta, in viso ed in parlare ed in costumi», Ardissino 200I: 367 ). De la mateixa manera, Martos (2013) argumenta que no figura a l'Ovide moralisé, a l'Ovide moralisé en prose ni a l'Ovidius moralizatus de Pierre Bersuire. A diferència d'aquestes versions, Corella afirma: «la primera figura mudar, donant-li'n altra que de mercader era vera ymatge» (Martos 200Ib: 24I). Però la informació també apareix a les Genealogiae deorum, XIII, 64 (Martos 20I3) i, segurament, en manuscrits glossats.

Encara al Parlament, Guillem de Vilarrassa explica el mite d'Escil-la i Minos, que figura al llibre vir de les Metamorfosis. En aquest cas, tot i que hi ha un element compartit entre Corella i Alegre, també figura en Bonsignori, que és la font principal d'addicions per a aquest episodi en Alegre. Així, el floc de cabells de Nisos, pare d'Escil.la, és porpra en Ovidi («splendidus ostro», Trepat \& Saavedra I930: vII, v. 9), però daurat en diverses versions medievals: Bonsignori, Corella, l'Ovide moralisé en prose (tal com fa notar Martos 20orb: 26I) i Alegre. Més endavant, Escil.la talla el floc de cabells del pare i els presenta a Minos com a senyal de victòria. Aquesta és la lliçó que contenen el poema d'Ovidi, la traducció italiana d'Arrigo de Simintendi (I330), molt fidel al text llatí, i també la reelaboració del mite per Corella. Per contra, l'Ovide moralisé, l'Expositio de Giovanni del Virgilio, Bonsignori i Alegre afirmen que el decapita i presenta el cap del pare com a trofeu a l'enemic. Aquesta variant medieval també es documenta en un gravat de l'edició de Colard Mansion de l'Ovide moralisé (Cy commence Ovide) de I484, en què els cabells de Nisos són pintats de color groc. ${ }^{15}$

El mite d'Orfeu, inclòs al Parlament, també forma part de l'apartat següent, tot i que és un exemple menys clar que el de Mirra.

Quant al mite de Biblis, narrat al llibre ix de les Metamorfosis i a la Lamentació de Biblis de Corella, Alegre (I494: f. 8or [78r]) introdueix un comentari breu sobre la naturalesa dels somnis en boca de la protagonista, que es desperta del somni incestuós amb el germà: «Vanes són totes les lurs promeses [dels somnis]», coherent amb la continuació del discurs ovidià, que no conté aquest incís. Es tracta d'un comentari similar al que Corella situa en aquest punt del monòleg de Biblis, però de sentit completament oposat: «Mas crech que los sompnis no són del tot vans» (Martos 20orb: 200). De fet, aquesta afirmació correspon al parer expressat per la veu narrativa del comentarista de les «Al.legories e morals exposicions» quan exposa el significat dels somnis a partir de Macrobi, però també a partir d'una anècdota personal del mestre d'Alegre, Giacomo Mirabella (Torró 1994: 228):

I5. Agraeixo a Anne McLaughlin l'ajut en la localització de la imatge. 
parlant ab ell [Giacomo Mirabella] dels somnis, y tenint que cathòlicament podem afermar algunes voltes somniar veritat, aprés de haver me declarat les sinch espècies ab autoritat vostra que ara he hoïdes, me dix com ell sovint veya en si la prova de la quarta spècia somniant les coses ab tal orde com aprés li seguían vellant. Moltes me’n dix, mes sol ne vull dir una que notí principal, y és que un jorn, dormint de sesta, somnià que venia un metge, amich seu, portant un libre grech vell y molt mal tractat, per mostrar lo y quin era, y que ell mirant lo trobave que éran los Evangelis, y, encare dormint, entrà per la cambra aquell que somniave $\mathrm{ab}$ un libre grech en què éran scrits los Evangelis. Lo qual eximpli, perquè el tench per molt sert per la auctoritat del quil' me recità, he volgut posar en lo present capítol.

En darrer lloc, també cal comentar el Raonament de Telamó i Ulisses, en el qual Corella reescriu l'episodi del llibre XIII de les Metamorfosis d'Ovidi. Un cop més, Alegre completa la informació que dona Ovidi (XIII, v. I62-I67) sobre la manera com Ulisses trobà Aquil.les disfressat de dona. Aquesta informació ja apareix en Corella. Una comparació entre els dos textos permet identificar-hi una sèrie d'elements comuns: (a) Ulisses es vestí de mercader per enganyar l'heroi, (b) Ulisses portà joies per a les dones, (c) Aquil.les es trobava al palau de Licomedes (Bonsignori esmenta Licomedes, però ho fa només com a rei de l'illa on se situa l'acció). Compareu els tres fragments:

Praescia uenturi genetrix Nereia leti / Dissimulat cultu natum et deceperat omnes, / In quibus Aiacem, sumptae fallacia uestis. / Arma ego femineis animum motura uirilem / Mercibus inserui; neque adhuc proiecerat heros / Virgineos habitus, cum parmam hastamque tenenti.

(Trepat \& Saavedra I930: XIII, vv. I62-I67) ${ }^{16}$

Tement la deessa Tetis les sdevenidores guerres per lo furt de la bella Elena, assajà ab cautelosa indústria mudar o mitigar los implacables e cruels fats, los quals, en los camps de Troya, a son fill Achilles de mort menasaven. Vestint aquell ab femenils vestidures, enganà a tots los grechs e fon maravella l'avisat Thelamó, ensemps ab ells, fos decebut. D'on les forces troyanes, aumentant de quada dia, allargaven nostra victòria, que los forts invencibles murs de Troya sol del fort Achilles podien ser vençuts. Perquè fon forçat a mi, fengint-me mercader, portàs moltes joyes a les donzelles en la casa del rey Licomedes, entre les quals, en àbit femenil, Achilles reposava, poch ansiós de sullar ses mans en sanch troyana. Mas, perquè entre tantes donzelles millor conegués lo vergonyós jove, ensemps ab les altres joyes yo portí una no poch gentil lança $[\ldots]$.

(Martos 200Ib: 132)

Avisada de la trista mort del fill, la mare de Achil.les, filla del gran Nereo, dissimulà aquel sots falsa cuberta de hàbit femení, ab lo qual enganà molts que per portar-lo a la nostra companyia foren tramesos y, entre ells, fon Àjaix enganat. Vengué la sort a mi, per a provar les forces de mon enginy, en descobrir l'amagat cavaller. Y, sabent que entre altres donzelles estave simulat sens que no era d'eles més conegut, fengint ésser mercader, entrí en lo palàcio de Licomedes, on aquelles estaven, portant toques e joyes de diverses maneres, que solen molt

I6. «Sabent per endavant la Nereida, mare d'Aquil.les, la mort que l'amenaçava, amaga el seu fill sota l'abillament, i tots s'havien deixat enganyar, i entre ells Àiax, per l'astúcia d'aquesta disfressa. Jo vaig posar, entre femenils mercaderies, armes que havien de moure un cor viril; i encara l'heroi no havia llençat les virginals vestidures que, mentre agafava un escut i una llança [...]» (Trepat \& Saavedra I932: vol. III, 53). 
Gemma Pellissa Prades

Algunes dades sobre la influència de les proses mitològiques de Corella

a les Transformacions de Francesc Alegre

les dones estimar; entre les quals havia mesclat algunes armes per moure l'ànimo del novell cavaller ha desig de aquelles. Y, seguint-se com havia pensat, mentre les altres estaven ocupades en mirar la merceria, vestit d'àbit de dona, Achil.les pres lo escut y la lança que yo havia portat.

(Alegre I494: f. 108v [106v)

Al mateix episodi, Ulisses declara sobre si mateix: "Tu uires sine mente geris, mihi cura futuri» (Trepat \& Saavedra I930: XIII, v. 363), ${ }^{17}$ que en Bonsignori, Corella i Alegre es presenta en forma del lloc comú del debat entre el cos i l'ànima, com aclareix Martos (200Ib: 135).

\section{DOS EXEMPLES IL·LUSTRATIUS DE LA INFLUENCIA DE CORELLA A LES TRANSFORMACIONS}

A diferència dels casos exposats amb anterioritat, que apunten a paral-lelismes Corella-Alegre que també podrien obeir a fonts comunes o a glosses que gaudiren d'una circulació àmplia, els dos exemples que es recullen en aquest apartat permeten provar la dependència entre les Lamentacions i el Parlament de Joan Roís de Corella i les Transformacions de Francesc Alegre.

Respecte de les Lamentacions, l'exemple se centra en el mite de Mirra, que Orfeu canta al llibre x de les Metamorfosis. A continuació s’identifiquen els elements compartits per Corella i Alegre. Així, a les Transformacions hi ha un avançament del diàleg en estil directe en el qual el pare de la jove li demana que triï pretendent. Alegre aprofita la reflexió que fa Orfeu quan introdueix la història de Mirra, en la qual diu que la donzella hauria pogut tenir el marit que desitgés (Ovidi: x, vv. 325-326) per situar la conversa en aquest punt. A la prosa de Corella el diàleg apareix al primer paràgraf de la història de Mirra (Martos 200Ib: 176), també en una posició avançada. Més endavant, al debat interior Mirra oposa la natura a les lleis humanes, les quals prohibeixen l'incest. Tant Corella (Martos 20orb: I77) com Alegre (I494: f. 87r [85r]) qualifiquen la natura de «liberal»; «natura remittit» en Ovidi (Trepat \& Saavedra I930: $\mathrm{X}, \mathrm{v} .330) .{ }^{18}$ Seguidament, cal fer notar que els dos autors catalans tradueixen de manera molt similar els versos d'Ovidi: «gentes tamen esse feruntur, / In quibus et nato genetrix et nata parenti / iungitur» (Trepat \& Saavedra I930: X, vv. 33I-333); ${ }^{19}$

I7. «Tu tens força sense enteniment, jo la cura del que ha de venir» (Trepat \& Saavedra I932: vol. III, 59).

I8. «La natura perdona» (Trepat \& Saavedra I930: vol. II, II5).

19. «Hi ha nacions tanmateix, diuen, on la mare s'uneix al fill i la filla al pare» (Trepat \& Saavedra I930: vol. II, II5). 
«E més, he hoït dir en una part del món habitar gents que no han vergonya que una sola sia mare e germana de sos fills» (Martos 200Ib: 177) / «si ver és lo que he hoït dir- en una part del món és consentit al pare de casar ab la filla i ab lo fill, la mare». Tot i que Alegre (I494: f. 87r [85r]) es manté més fidel al poema llatí, l'inici de la frase és molt similar.

És encara més significatiu que quan Mirra descriu el marit que vol («similem tibi», Trepat \& Saavedra I930: x, v. 394), ${ }^{20}$ Corella reescriu: "Yo desige marit que en res a vós no dessemble» (Martos 200Ib: I76), de la mateixa manera que Alegre (I494: f. 87v [85v]) tradueix: «Senyor, yo volria marit que en res a vós no desemblàs». El paral.lelisme textual és evident; en canvi, en Giovanni del Virgilio Mirra afirma «Ego vellem simile tibi» (Ardissino 200I: 505) i en Bonsignori «Io voria solo te» (Ardissino 200I: 489).

Més endavant, davant de l'interrogatori de la dida, Mirra exclama que sa mare és afortunada a causa del marit que té "hactenus, et gemuit» (Trepat i Saavedra I930: $\mathrm{X}, \mathrm{v} .423){ }^{21}$ Les expressions triades per Corella i per Alegre per tancar l'exclamació fan referència explícita a la vergonya: «E parlar més avant no·m conssentí vergonya» (Martos 20orb: I82) / «no consentint-li de més dir la vergonya» (Alegre I494: f. 88r[86r]). També hi ha coincidències textuals en la traducció dels versos següents d'Ovidi amb la referència explícita al llit conjugal: «Perque nouem noctes Venerem tactusque uiriles / In uetitis numerant» (Trepat \& Saavedra 1930: X, v. 434-435); ${ }^{22}$ "Lexaven per nou dies los lits frets a sos marits» (Martos 200Ib: I82); «E per nou continuades nits dexaven las mullers lo lit de lurs marits» (Alegre I494: f. 88r [86r]).

De la mateixa manera, Bonsignori, Corella i Alegre fan que la dida insisteixi en la bellesa de la noia que ofereix a Cínires i, en el moment de la consumació de l'acte, els dos textos catalans fan èmfasi en la sang vessada per Mirra: "Accipit obsceno genitor sua uiscera lecto» (Trepat \& Saavedra 1930: X, v. 465); ${ }^{23}$ "Lo re Cinnara la presa e pusela sul letto» (Ardissino 200I: 492); "tenyint de verge sanch aquells tàlems en los quals fuy concebuda» (Martos 200Ib: I83); "Acceptà lo pare en lo culpable lit la sua sanch» (Alegre I494, f. 88v [86v]).

Finalment, Bonsignori i Alegre fan que el llum amb el qual el pare il.lumina la identitat de l'amant el porti un patge, de manera que es posa de manifest la combinació de diferents fonts per a la traducció del mite: «inlato lumine» (Trepat \& Saavedra

20. «Semblant a tu» (Trepat \& Saavedra I930: vol. II, II5).

2I. "Això fou tot i gemegà» (Trepat $\&$ Saavedra 1930: vol. II, II7).

22. «Durant nou nits miren com a prohibits el plaer de Venus i els contactes virils» (Trepat \& Saavedra I930: vol. II, II7).

23. «El pare rep la filla de les seves entranyes al seu llit impur» (Trepat \& Saavedra I930: II, II8).

Caplletra 66 (Primavera, 2019), p. 15-32 
Gemma Pellissa Prades

Algunes dades sobre la influència de les proses mitològiques de Corella

a les Transformacions de Francesc Alegre

1930: X, v. 473); $;^{24}$ «fecit portari lumen» (Del Virgilio, Iorr; extret d'Ardissino 200I: 506); «e sì chiamò uno suo servo e fece arricare lo lume» (Ardissino 200I: 492); «feu portar a un patge una atxa encesa» (Alegre I494, f. 88v [86v]).

En definitiva, el mite de Mirra permet demostrar amb paral.lelismes lèxics la influència de Corella en la traducció d'Alegre al costat d'altres fonts.

Tambéés força clarl'exemple extret del Parlament; concretament de la intervenció de Joan Escrivà, en la qual relata la història d'Orfeu i Eurídice. Aquest mite pertany al llibre x de les Metamorfosis. Per contrast amb el poema d'Ovidi, Bonsignori, Corella i Alegre fan referència al «mortal verí» (Martos 20orb: 253) / «negre verí» (Alegre I494: f. 83r [8rr]) de la picada de la serp que causa la mort d'Eurídice, mentre que Ovidi no l'esmenta fins als vv. 23-24. Al mateix episodi, el vers d'Ovidi «pulsisque ad carmina neruis» (Trepat \& Saavedra 1930: x, v. I6) ${ }^{25}$ es converteix en Corella en: «començà temprant moure los fils de la acordada arpa» (Martos 20orb: 253) i en Alegre (I494: f. 83r [8Ir]): «començant ab sos dits a moure les cordes de la arpa», que posa de manifest els paral-lelismes textuals entre les dues versions. A més a més, els dos autors catalans prossegueixen el passatge amb l'esment de la veu d'Orfeu, que canta.

En conclusió, més enllà d'un model de prosa de prestigi compartit per Corella i Alegre i de l'elaboració sentimental de certs passatges, hi ha indicis que suggereixen la dependència textual de les Transformacions respecte de l'obra de Corella. Concretament, els exemples del mite de Mirra, en el qual hi ha paral-lelismes lèxics entre la redacció de les Lamentacions i la traducció d'Alegre, permeten provar la influència de Corella. També és força evident en els dos casos aportats en relació al mite d'Orfeu, en aquest cas narrat en una altra prosa de Corella, el Parlament. La resta d'exemples que s'han aportat, tot i que apunten en la mateixa direcció, podrien obeir a una font comuna. Més endavant, Alegre emprarà la Tragèdia de Caldesa i potser les proses mitològiques de Corella com a model per a compondre la Faula de Neptuno i Diana. Si Alegre hagués conegut el Raonament de Telamó i Ulisses, les Lamentacions, el Parlament i la Lamentació de Biblis, a més de la Tragèdia de Caldesa, la còpia que hauria posseït de les obres de Corella hauria estat semblant al Cançoner de Maians (I482-I5OO).

Gemma Pellissa Prades

Universitat de Barcelona

gemmapellisa@gmail.com

ORCID 0000-0003-2455-9717

24. "havent fet portar una torxa» (Trepat \& Saavedra I930: vol. II, II9). 25. «i havent polsat les cordes cantà» (Trepat \& Saavedra I930: II, IO5). 


\section{REFERÈNCIES BIBLIOGRÀFIQUES}

Alcina, J. (1998) «El poeta como Dios: la poética de Landino en España (de Francesc Alegre a Alfonso de Carvallo)", Salina, I2, p. 40-49.

Alegre, F. (I494) Transformacions, Barcelona, Biblioteca de Catalunya (Bon IO-VI-29), imprès per Pere Miquel.

Ardissino, E., ed. (20or) Giovanni Bonsignori, Ovidio Metamorphoseos Vulgare, Bolonya, Commissione per i testi di lingua.

Avenoza, G., L. Soriano \& V. Beltran, dir. (1997-) BITECA (Bibliografia de Textos Antics Catalans, Valencians $i$ Balears), Berkeley, University of California, The Bancroft Library. [<http://vmiz6.lib.berkeley.edu/BANC/philobiblon/biteca_en.html>; consulta: 13/06/20I8.]

BADIA, L. (1986) «Per la presència d'Ovidi a l'Edat Mitjana, amb notes sobre les traduccions de les Heroides i de les Metamorfosis al vulgar", dins Studia in honorem prof. M. de Riquer, I, Barcelona, Quaderns Crema, p. 39-7I.

Cabré, L., M. Ferrer \& J. Pujol (20iI) TRANSLAT. Traduccions al català medieval fins a I50o, Bellaterra, Universitat Autònoma de Barcelona. [<http://www. translatdb.narpan.net/index.php>; consulta: 13/06/2018.]

Compagna, A. M. (20I4) «Corella i Alegre: reescriure o traduir i comentar Ovidi?», dins A. Ferrando (ed.), Joan Rois de Corella i el seu món, València, Institució Alfons el Magnànim, p. 449-464.

Duran, E. \& J. Solervicens (I996) Renaixement a la carta, Barcelona, Universitat de Barcelona / Eumo, p. 34-42.

Gómez, F. J. (2015) «Joan Roís de Corella», dins L. Badia (dir.), Història de la literatura catalana, III, Barcelona, Enciclopèdia Catalana / Editorial Barcino / Ajuntament de Barcelona, p. 2II-250.

Guthmüller, B. (1997) Mito, poesia, arte. Saggi sulla tradizione ovidiana nel rinascimento, Roma, Bulzoni.

Hauf, A., ed. (1995) Joanot Martorell, Tirant lo Blanch (València I490), València, Tirant lo Blanch.

Hernando i Delgado, J. (2002) «Del llibre manuscrit al llibre imprès. La confecció del llibre a Barcelona durant el segle xv. Documentació notarial», Arxiu de Textos Catalans Antics, 21, p. 257-603.

MarTí, S. (I997) «El Cançoner del Marquès de Barberà (SI-BMI). (Descripció codicològica)", Boletín Bibliográfico de la Asociación Hispánica de Literatura Medieval, II, p. 463-502. 
Gemma Pellissa Prades

Algunes dades sobre la influència de les proses mitològiques de Corella

a les Transformacions de Francesc Alegre

Martos, J. L., ed. (200Ia) Fonts i seqüència cronològica de les proses mitològiques de Joan Rois de Corella, Alacant, Universitat d'Alacant.

—ed. (2001b) Lesprosesmitològiques de Joan Roís de Corella, Alacant/Barcelona, Institut Interuniversitari de Filologia Valenciana / Publicacions del'Abadia de Montserrat.

— (2013 [Ia ed. 2003]) «La presència de Boccaccio en les proses mitològiques de Joan Roís de Corella», Biblioteca Virtual Miguel de Cervantes. [<http://www.cervantesvirtual.com/obra/la-presencia-de-boccaccio-en-les-proses-mitologiquesde-joan-rois-de-corella; consulta: ז3/06/20I8.]

Pellissa Prades, G., ed. (2016) Francesc Alegre. Obres de ficciósentimental, Alessandria, Edizioni dell'Orso.

— (2017) «The Italian Sources of the Catalan Translation of Ovid's Metamorphoses by Francesc Alegre (Isth c.)", Zeitschrift für romanische Philologie, 133(2), p. 443-47I.

Pujol, J. (2002) «Expondre, traslladar i reescriure clàssics llatins en la literatura catalana del segle XV", Quaderns: Revista de Traducció, 7, p. 9-32.

Rubió i Balaguer, J. (I993) Llibreters $i$ impressors a la Corona d'Aragó, XI, Barcelona, Publicacions de l'Abadia de Montserrat.

Torró, J. (1994) «"Officium poetae est fingere”: Francesc Alegre i la Faula de Neptuno i Dyana”, dins L. Badia i A. Soler, Intel.lectuals i escriptors a la Baixa Edat Mitjana, Barcelona, Curial / Publicacions de l'Abadia de Montserrat, p. 22I-242.

Trepat, A. M. \& A. M. SaAvedra, trad. (I929-1932) Publi Ovidi Nasó, Metamorfosis, I-III, Barcelona, Fundació Bernat Metge, 40, 49 i 62.

VInge, L. (1967) The Narcissus Theme in Western European Literature Up to the Early Igth Century, Lund, Gleerups. 